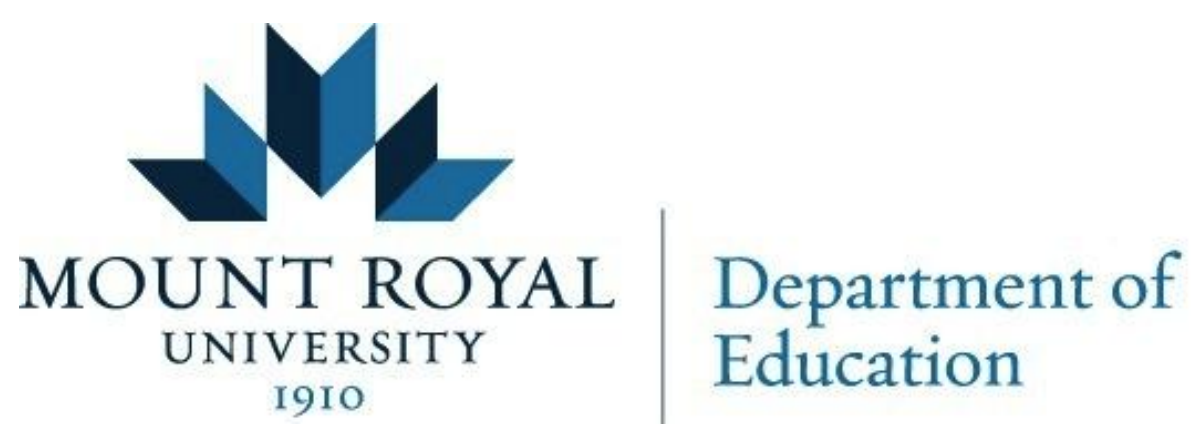

Mount Royal Undergraduate Education Review

Volume 1(3)

Fall 2015

\title{
Language acquisition through digital games
}

Sarah Vanderwal, Mount Royal University

Link to Digital Story

\begin{abstract}
This study strives to answer the question "Do educational video games focusing on language provide a better learning experience than traditional language education?" Research was focused on the differences between the language acquisition and enjoyment that these games provide in contrast to traditional pen-and-paper teaching methods. A literature study showed mixed results as to the effectiveness of these games. A survey, as well as interviews with experts in the field were conducted. This study concluded that while language games are more enjoyable to the student than traditional teaching methods, their use in the classroom does have several disadvantages. This led to the conclusion that while digital language games can be useful teaching tool, they should be used in conjunction with more traditional methods.
\end{abstract}




\section{Introduction}

Technology has become a part of our day-to-day lives. It plays a large part in our communication and learning. As a result, educational technology is a topic that is very important for future teachers to explore. I am particularly interested in the role that educational technology plays in language education. Languages interest me greatly, both the acquisition and use of language as well as the grammatical structures and rules that form different ones. As a result I have chosen to take the TESL minor, giving me the chance to gain a deeper understanding of how to instruct children who are learning English as their second language.

As a student I was taught languages using only traditional pen-and-paper methods, and while those did work well for me they were boring and at times difficult to remember. I want to explore the potential benefits that language learning games could have on student learning and retention. As a result the question that I have chosen for inquiry is "Do educational video games focusing on language provide a better learning experience than traditional language education?"

\section{Background}

Many students find language learning to be boring and regard it as a chore that they must complete in order to do well in school. Much research has been done into the benefits of game based language learning, both on increasing students' enjoyment and on the benefits it provides to students' learning and memory of the language.

Ansteeg (2015) introduces an educational game that includes narrative and role-playing elements, with learning at the core of its mechanics. A user study was conducted to determine the game's efficiency, in which it was compared to two other learning methods focused on both enjoyment and vocabulary retention. This study found that the game based method was not only significantly more enjoyable to the user, but it also performed within $10 \%$ of the the efficiency of 
pure vocabulary exercises. This paper also gives an overview of existing language learning tools (Angsteen, 2015).

The study by Laio and Chen (2012) exposed 79 low-motivated Taiwanese students with little to no understanding of English to games designed to enhance their vocabulary. After analysis it was found that vocabulary games utilized as either an independent part or an entire program of study do facilitate the lexical growth and retention of those using them. Laio and Chen (2012) go on to discuss ways in which such games could be used in the classroom as a supplement to traditional learning or as a remedial program for those needing extra help.

Another study investigated inference-based computer games that were imbedded in eBooks to teach English vocabulary to Chinese undergraduate students. Smith, Li, Drobisz, Park, Kim and Smith (2013) compared the effectivity of these games to that of hardcopy books used for vocabulary retention and looked for a relationship between how well students performed on the games and how well they performed on later vocabulary tests. By using pre- and post- tests otowas found that the students who used the games learned a significant amount more vocabulary than those who used traditional methods such as hard-copy texts and lists of vocabulary words (Smith et al., 2013).

Taheri (2014) investigated the effect that language learning games have on vocabulary retention of Iranian elementary children. The children were split into a control group who studied language in traditional ways such as drills and definitions, and an experimental group who were taught using language games. After three posttests (the third being given six weeks after the course had been completed) the participants' vocabulary retention was analyzed. This analysis showed that the game method had greater results in the delayed time tests than in the immediate ones (Taheri, 2014). 
The paper by Young and Wang (2014) is focused on a study of the effects of a system in which Taiwanese English-language learners were taught using a gaming system that included automatic speech recognition technology. The experiment split subjects into a group that learned using only drills, and a group that used both drills and game-based practice. While the learners who used the game-based method performed better in the area of pronunciation, it was found that those who used only drills were better able to retain the vocabulary that they had learned. (Young \& Wang, 2014).

This previous research shows mixed results as to the usefulness of game-based language learning, with some studies finding that it increases students' learning and others finding that makes little to no difference. The findings of these studies give an overview of the reasons for and against using game-based technology in the classroom as a teaching tool.

\section{Research Context}

My data was gathered from my classmates and two experts in the field. Eighteen of my classmates and friends participated in the survey. One of the experts was a Mount Royal professor and the other was a language teacher at Bearspaw Christian School. The participants in my research were informed that I have received ethics certification from the Government of Canada and understood that their participation was voluntary and their answers were anonymous.

\section{Methods of Investigation}

I used an online survey through Google Forms to collect the majority of my data. I also collected data through email interviews with experts in the field, asking them about both advantages and disadvantages of using game-based technology as a language teaching tool. My data was analyzed through the use of Google Spreadsheets to create charts and graphs, and by comparing positive and negative results and seeing if there is any visible indication of games 
providing a better learning experience. My data has been organized according to the perspective that it came from- a teacher or a learner, and has been analyzed through a comparison of the results that I received.

\section{Findings}

In order to discover if educational video games focusing on language provide a better learning experience than traditional language education I conducted a survey. The first question of my survey focused on determining what role the participant plays in the education process. Out of 18 participants, $13(76.5 \%)$ were students, $3(17.6 \%)$ were parents, and $1(5.9 \%)$ was a teacher. 1 person did not answer this question. These results show that the majority of people studied who have interacted with this type of technology have done so as a student focused on learning the language for themselves. Almost everyone who took my survey was a student.

\section{Are you a:}

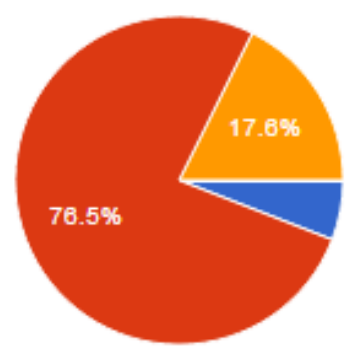

$\begin{array}{rrr}\text { Teacher } & \mathbf{1} & 5.9 \% \\ \text { Student } & \mathbf{1 3} & 76.5 \% \\ \text { Parent } & \mathbf{3} & 17.6 \% \\ \text { Administrator } & 0 & 0 \% \\ \text { Other } & 0 & 0 \%\end{array}$

Figure 1. Responses to survey question \#1.

A later question asked participants about the effectiveness of these games on their learning. This question was asked both to learners and to teachers in order to understand this from a wide perspective. Those who had used digital games to learn a language themselves provided mixed results on the effectiveness of this method. Most results were positive, with a few being neutral and very few being negative. However, those who had taught language using digital games provided almost totally positive results for their students' learning. 
If you have used a language game, did you find that it helped you to remember what you had learned?

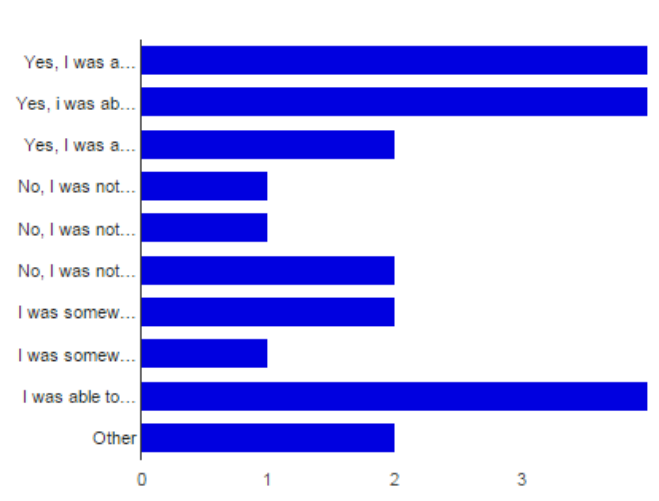

Figure 2. Responses to survey question \#5.

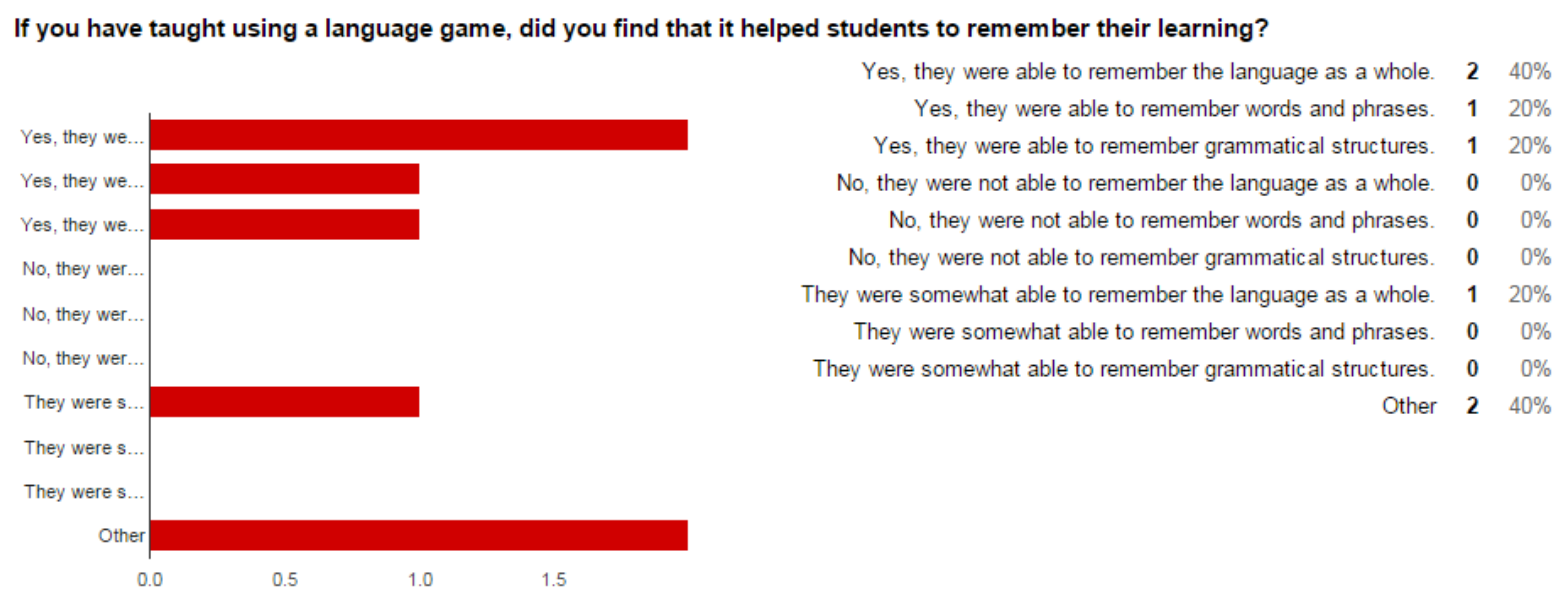

Figure 3. Responses to survey question 10.

Another potential advantage to game-based language education is the ability of students to enjoy their learning more than they would with traditional methods. Participants in my survey were again asked about this from both a learning and teaching perspective. Almost all people who had used digital games to learn language found it more enjoyable than traditional methods. Also, nearly all people who had used digital games to teach language responded that their students had found it more enjoyable than traditional methods. This data suggests that using games for language acquisition does provide a better learning experience in terms of student enjoyment than traditional education methods do. 


\section{Did you find game-based technology more enjoyable than traditional education methods?}

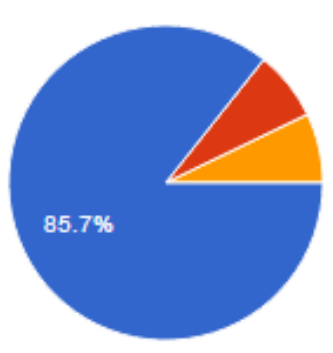

$\begin{array}{rrr}\text { Yes } & \mathbf{1 2} & 85.7 \% \\ \text { No } & \mathbf{1} & 7.1 \% \\ \text { Other } & \mathbf{1} & 7.1 \%\end{array}$

Figure 4. Responses to survey question 6.

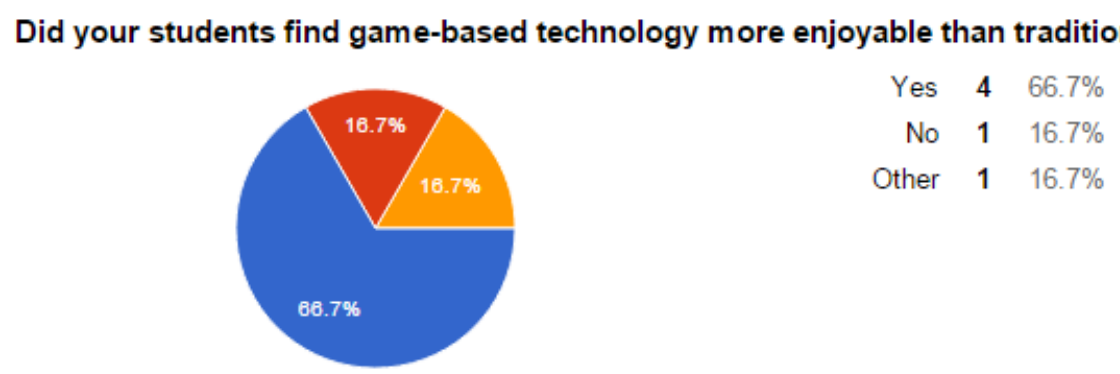

Figure 5. Responses to survey question 11.

While researching this subject I also conducted email interviews with two experts in the field. The questions I asked where "Are there any advantages or disadvantages to using digital games to teach language?" and "How can this technology be used in the classroom?" The first of my experts, a professor at Mount Royal University, discussed the ways in which language can be used in online interactions. Her suggestion was to use digital technology to create realistic situations in which to practice using language, such as creating a simulation of an online shopping experience, where students have to describe what it is that they are selling $(\mathrm{H}$. Roessingh, personal communication, November 18, 2015). H. Roessingh mentioned that while there are many possibilities for this technology to assist in learning, there are disadvantages to it as well, such as possible addictions to technology and the dangers that come with online interactions such as stalking and cyberbullying (personal communication, November 18, 2015). 
The other expert that I asked these questions of is a language teacher at Bearspaw Christian School. M. Laing cited the advantages of digital games as being engagement, independence, triggering different parts of the brain than traditional education methods, and allowing students to personalize their learning needs (personal communication, November 23, 2015). According to her, some disadvantages may be that students will simply click through the game to finish it without actually learning, that an overuse of screens causes a lack of personal interaction, that such methods do not work for every student, and that it is easy for students to become distracted with this type of learning (M. Laing, personal communication, November 23, 2015). In both interview the experts expressed that while there are advantages to using digital gaming technology for learning, there are also disadvantages.

\section{Conclusions and Recommendations}

The results of this study have shown mixed results as to the effectivity of digital games to teach language. While many sources reveal that these games do indeed provide a better learning experience than traditional education methods, many disadvantages have also come to light. From an analysis of the information that I have collected I believe that using digital games can help students to have a more fun and productive language learning experience. However, due to the many disadvantages it seems that the best way to use these games is in conjunction with traditional education methods. If this technology is used in a directed manner that facilitates student learning, and in conjunction with pen-and-paper methods that stimulate alternate areas of the brain, it can be a very powerful tool to assist in students' learning. In my future teaching I will likely use game-based learning as an addition to traditional pen-and-paper methods to teach language acquisition.

Additional research on this topic should focus on the types of games that are the most 
effective, specifically which area of language is most easily acquired through game-based learning.

\section{References}

Ansteeg, L. W. (2015). Incidental lexicon acquisition through playful interaction. International Journal of Emerging Technologies in Learning, 10(1), 4-10. http://dx.doi.org/ 10.3991/ijet.v10i1.4156

Liao, H.-C., \& Chen, M. (2012). Effects of vocabulary games on lexical growth and retention of low-motivated EFL learners in Taiwan. Asia-Pacific Education Researcher, 21(3), 564-575.

Smith, G.G., Li, M., Drobisz, J., Park, H.-R., Kim, D., \& Smith, S. D. (2013). Play games or study? Computer games in eBooks to learn English vocabulary. Computers and Education, 69, 274-286. http://dx.doi.org/10.1016/j.compedu.2013.07.015

Taheri, M. (2014). The effect of using language games on vocabulary retention of Iranian elementary EFL learners. Journal of Language Teaching \& Research, 5(3), 544-549. http://dx.doi.org/10.4304/jltr.5.3.544-549

Young,S.-S.-C., \& Wang, Y.-H. (2014). The game embedded CALL system to facilitate english vocabulary acquisition and pronunciation. Educational Technology and Society, 17(3), 239-251. 